\title{
ACUPUNCTURE AS A NON-PHARMACOLOGICAL TREATMENT OPTION FOR FIBROMYALGIA: A SYSTEMATIC REVIEW
}

Matheus Rodrigues Nóbrega ${ }^{1, \star}$, Laura Oliveira Rolim de Carvalho², Lucas Meneses Alverga ${ }^{1}$, Maria Gabriela Gondim Gomes ${ }^{1}$, Talinny Zubisarrannya Teoclaudylyanny Teotônio de Farias ${ }^{1}$, Alice Maria Câmara ${ }^{3}$, Camilla Nóbrega Rolim¹

1.Faculdade de Ciências Médicas da Paraíba, João Pessoa (PB), Brazil. 2.Faculdades Integradas de Patos, Patos (PB), Brazil. 3.Universidade Estadual do Rio Grande do Norte, Mossoró (RN), Brazil.

*Corresponding author: matheusjpnobregaa@gmail.com

\section{BACKGROUND}

Fibromyalgia (FM) is a complex but very common chronic pain syndrome. It is characterized by the presence of severe pain throughout the body, fatigue and sleep disorders, leading to a significant decrease in the individual's quality of life. Part of the treatment of this pathology is done using nondrug measures, such as physical exercise, cognitive behavioral therapy and acupuncture. MATERIALS AND METHODS: The data of this work were taken from scientific productions present in the databases of PubMed and MEDLINE, and articles from randomized clinical trials were chosen. Studies that did not address data related only to acupuncture and fibromyalgia, reviews and case reports, articles with more than five years of publication and that were not in English were excluded. To search for articles, the following keywords "fibromyalgia" and "acupuncture" were used and, finally, three articles were selected (Table 1). The data were analyzed using Microsoft softwares such as Word and Excel.Table ..

\begin{tabular}{cc}
\hline Research steps & Resulted \\
\hline Acupuncture AND Fibromyalgia & 218 articles \\
\hline Inclusion and exclusion & 27 articles \\
\hline Sample body & 3 articles
\end{tabular}

\section{RESULTS}

The sample size varied between studies from 50-162, but there were 287 participants with fibromyalgia in total. All studies showed an improvement in symptoms, with a decrease in pain intensity. It was observed that the simulated group also had an attenuation of symptoms, which does not exempt the effectiveness of the treatment done with real acupuncture. Two of the studies evaluated the effect of acupuncture over the long term, one for up to 3 months and the other for a year, highlighting the benefits of this therapy.

\section{CONCLUSION}

Acupuncture is effective for reducing the pain of fibromyalgia, having an effect in the short and long term, which makes it eligible for the treatment of this pathology.

\section{REFERENCES}

1. Lackner A, Stradner MH, Hermann J, Unger J, Stamm T, Graninger WB, Dejaco C. Assessing health-related quality of life in primary Sjögren's syndrome-The PSS-QoL. Semin Arthritis Rheum. 201;48(1):105-10. https://doi.org/10.1016/j.semarthrit.2017.11.007

2. Uğurlu FG, Sezer N, Aktekin L, Fidan F, Tok F, Akkuş S. The effects of acupuncture versus sham acupuncture in the treatment of fibromyalgia: a randomized controlled clinical trial. Acta Reumatol Port. 2017;42(1):32-7

1. Vas J, Santos-Rey K, Navarro-Pablo R, Modesto M, Aguilar I, Campos MÁ, Aguilar-Velasco JF et al. Acupuncture for fibromyalgia in primary care: a randomised controlled trial. Acupunct Med. 2016;34(4):257-66. https://doi.org/10.1136/acupmed-2015-010950 